\title{
SURFACE ANESTHETIC EFFECT OF COMPOUND LIDOCAINE CREAM IN CHILDREN UNDERGOING PTOSIS OPERATION AND GENERAL ANESTHESIA
}

\author{
Z. Du, X. Zhang, S. Zhu \\ Anesthesiology, Hunan Children's Hospital, Changsha, China
}

Objective: To observe the efficacy of lidocaine-prilocaine cream(EMLA) preventing complications of endotracheal intubation in children undergoing ptosis operation.

Methods: Sixty children undergoing ptosis operation were randomized into three groups of control(group C), two surface anesthesia groups of L1 and L2with 20 cases each .SBP, DBP and HR before and each timing after intubation , at bandaging eyes and extubation, extubation time, occurrence of movement during surgery, degree of restlessness during extubation and the incidence of complications in 24 hours after extubation were recorded.

Results: The values of SBP, DBP and HR were increased after intubation in each group .There is no difference between group $\mathrm{C}$ and surface anesthesia groups before and $2 \mathrm{~min}, 10 \mathrm{~min}$ after intubation $(\mathrm{P}>0.05)$. But the variation of group $C$ was distinctly higher compared with surface anesthesia groups $30 \mathrm{~min}$ and $1 \mathrm{hr}$ after intubation and at bandaging eyes and extubation $(\mathrm{P}<0.05)$. The surface anesthesia groups L1 and L2 is almost the same $(\mathrm{P}>0.05)$. Extubation time is also close between these three groups $(\mathrm{P}>0.05)$. Compared with groups of $\mathrm{C}$, the scores of restlessness in groups of $\mathrm{L} 1$ and $\mathrm{L} 2$ were significantly lower $(\mathrm{P}<0.05)$. The incidence of pharyngeal complication after extubation was higher in group $\mathrm{C}$ than group L1 and group L2(P< $0 \cdot 05)$.

Conclusion: Although surface anesthesia with EMLA can not efficiently inhibit cardiovascular effects resulting from endotracheal intubation, this method can relieve the stress reaction caused by tracheal catheter during moderate and long time surgery and also can significantly prevent the restlessness and incidence of complications after extubation. 